of bioequivalence of metered dose inhalers, some research evidence relating the cost of treatment of asthma to the quality of patients' lives, and a more appropriate method of educating health professionals than such unreferenced reports.

DERMOT P RYAN* General practitioner

Woodbrook Medical Centre,

Loughborough,

Leicester LE11 $1 \mathrm{NH}$

Prestwood Avenue Surgery,

Kenton

Middlesex AJ3 8JZ

1 Prescription Pricing Authority. Asthma and inhaler therapy. Newcastle upon Tyne: PPA, 1994.

2 Saarelainen P, Sovijarvi ARA. Comparison of acute bronchodilatation effects of two preparations of salbutamol aerosol in dilatation effects of two preparations of salbutamol
asthma. Current Therapeutic Research 1991;50:224-30.

3 Food and Drug Administration. Interim guidance for documenttion of in vivo bioequivalence of albuterol inhalation aerosols. Washington: FDA, 1994.

^Both authors are members of the steering group of the General Practitioners in Asthma Group, which is supported by an educational grant from Allen and Hanburys.

\section{Virtual reality surgery in otorhinolaryngology}

EDIToR,-Anthony Hinton and Victoria MooreGillon mention that virtual reality surgery could well be the next development in otorhinolaryngology. ${ }^{1}$ Since 1992 we have used a Viewing Wand (ISG Technology, Mississauga, Ontario, Canada) to aid ear, nose, and throat surgery. ${ }^{2}$ The wand is an intraoperative image guidance system with a proprioceptive robot-like arm attached to a standard three pin Mayfield head rest. Using preoperative computed tomograms or magnetic resonance imaging scans, the wand creates almost instantaneous three dimensional or triplanar (saggital, coronal, and axial) computerised reconstructions, showing the exact position of the tip of the arm on the reformated images.

The wand has proved extremely useful in aiding peroperative navigation, in identifying the relation and proximity of important anatomical structures, and in the assessment of the extent of resection of lesions. We have used it to aid the resection of many lesions in ear, nose, and throat surgery, including large primary cholesteatomas, glomus jugulare tumours, acoustic neuromas, and clivus chordomas. With a special bayonet probe, it has been used to fenestrate the sphenoid and create a minimally invasive approach to the pituitary fossa (M I Torrens, D R Sandeman, proceedings of the second international skull base symposium, St Petersburg, 1994). We also plan to use it to aid orientation during functional endoscopic sinus surgery, in which it should prove invaluable in identifying the lamina papyracea and the floor of the anterior cranial fossa. We have little doubt that such technology will prove to be of benefit in many more aspects of otorhinolaryngology.

A SIMON CARNEY

Former senior house officer in otolaryngolog

DAVID BALDWIN

Southmead Hospital,

Westbury on Trym

Bristol BS10 5NB

NITIN PATEL Registrar in neurosurgery DAVID SANDEMAN Frenchay Hospital,
Brisol BS16 1LE Consultant neurosurgeon

1 Hinton A, Moore-Gillon V. Recent advances: otorhinolaryngology. BMO 1994;309:651-4. (10 September.)

2 Zinreich SJ, Robles HA, Long DM, Bryan RN. 3D imaging for neurosurgery. In: Tos M, Thomsen J, eds. Acoustic neuroma. Amsterdam, New York: Kugler, 1991:109-18.

\section{Appropriateness of referrals to hospital}

EDrToR,-In their study of the appropriateness of referrals Glyn Jones Elwyn and Nigel $\mathrm{CH}$ Stott used the concept of avoidable referrals.' They found that $38 \%$ of the referrals studied over one year had been avoidable, whereas in a larger study Fertig et al found $15.9 \%$ of referrals to have been possibly inappropriate when judged against locally determined guidelines. ${ }^{2}$ Thirty two of the avoidable referrals in the authors' study were considered to have been due to lack of resources, and it is perverse to judge the decision on referral in these cases as inappropriate. If these cases were included in the appropriate group the proportion of inappropriate or avoidable referrals would fall to $15 \cdot 5 \%$, almost exactly the same as Fertig et als finding and well within their $95 \%$ confidence interval $(11 \cdot 8 \%$ to $20 \%)$. $^{2}$

Since inappropriate referrals do not seem to explain variation in referral rates the authors' approach, which classifies the reason for referral, may offer a way forward; perhaps the proportions of the types of referral vary between doctors with high and low referral rates. ${ }^{12}$ Unfortunately, it is not clear how significant was the agreement between the referrer's assessment and that of his collaborator, and it would be interesting to know what they disagreed about (nor are we told the referral rate per 100 consultations in this study). It would have been helpful if at least two other general practitioners had assessed the referrals so that we could know both how closely they agreed with the published assessments and whether the referrer's assessments were significantly different from those of the others; the degree of agreement can be measured by calculating $\kappa$ for each pair.

Two important points made by this study are the extent to which referrals in general practice are necessitated by lack of resources and inadequate communication with hospitals. The second point clearly needs to be addressed, but the first is not so clear cut as may be assumed. For example, if general practitioners were able to carry out upper gastrointestinal endoscopy in their surgeries they would not have to refer patients for this investigation; the costs in terms of equipment and time, however, are so great that it is almost certainly more economical for endoscopy to continue to be done in the secondary sector. We should be wary of the suggestion that a reduction in referral to hospital is necessarily desirable.

D T LIPMAN

Medical Centre,

Westerhope,

Newcastle upon Tyne NE5 2LH

1 Jones Elwyn G, Stott NCH. Avoidable referrals? Analysis of 170 consecutive referrals to secondary care. $B M \mathcal{F} 1994 ; 309: 576-8$. (3 September.)

Fertig A, Roland M, King H, Moore T. Understanding variation in rates of referral among general practitioners: are inappropriate referrals important and would guidelines help to reduce rates? $B M$ F 1993;307:1467-70.

3 Sackett DL, Haynes RB, Guyatt GH, Tugwell P. Clinical epidemiology $-a$ basic science for clinical medicine. New York: Little, Brown, 1991:24-34.

\section{Therapeutic use of bisphosphonates in oncology}

EDITOR,-Juliet E Compston's review of the therapeutic use of bisphosphonates understates thei value in oncology. ${ }^{1}$ In addition to their efficacy in hypercalcaemia they are effective in relieving bone pain and in preventing some of the skeletal complications associated with both advanced breast cancer and multiple myeloma.

High doses of intravenous pamidronate have consistently been shown to relieve pain in around half of patients with bone metastases from breast cancer and induce healing of lytic bone lesions in 20-25\%. ${ }^{2}$ Intravenous pamidronate also prolongs the time to progression in bone when patients with advanced breast cancer are treated with palliative combination chemotherapy. ${ }^{3}$ Randomised controlled clinical trials of oral bisphosphonates in breast cancer ${ }^{4}$ and multiple myeloma ${ }^{5}$ have shown that long term administration reduces pathological fractures, the incidence of hypercalcaemia, requirements for palliative raidotherapy, and the severity of pain. Numerous animal and laboratory studies have indicated that bisphosphonates may prevent bone metastases, and clinical trials investigating this are in progress.

Metastatic bone disease is the most clinically important skeletal disorder after osteoporosis. The bisphosphonates are an important new modality of treatment with useful effects on quality of life and skeletal morbidity.

Yorkshire Cancer Research Campaign

RE COLEMAN Senior lecturer

Department of Clinical Oncology,

Department of Clinical Oncology,
Weston Park Hospital NHS Trust,

Wheffield S10 2SJ

1 Compston JE. The therapeutic use of bisphosphonates. $B M$ 1994;309:711-5. (17 September.)

2 Coleman RE, Purohit OP. Osteoclast inhibition for the trearment of bone metastases. Cancer Treat Rev 1993;19:79-103.

3 Conte PF, Giannessi PG, Latreille J, Mauriac L, Koliren L, Calabresi F, et al. Delayed progression of bone metastases with pamidronate therapy in breast cancer patients: a randomised phase III trial. Ann Oncol 1994;5(suppl 7):41-4.

4 Van Holten-Verzantvoort AT, Kroon HM, Bijvoet OLM, Cleton FJ, Beex LVAM, Blijham G, et al. Palliative bone treatment in patients with bone metastases from breast cancer. $f$ Clin Oncol 1993;11:491-8.

5 Lahtinen R, Laakso M, Palva I, Virkkunen P, Elomaa I, for the Finnish Leukaemia Group. Randomised, placebo-controlled multicentre trial of clodronate in multiple myeloma. Lancet 1992;340:1049-52.

\section{Imported falciparum malaria}

EdrToR,-A television programme during the summer (World in Action, "Dying for a Holiday," Granada TV, 18 July 1994) that reported on cases of falciparum malaria in tourists returning from tropical holidays mirrored experience that we have reported in British troops. ${ }^{1}$ The programme relayed criticism from bereaved relatives about general practitioners' inadequate advice and awareness of the condition.

The striking difference between our cohort of troops and most tourists is that before duty in tropical areas the troops receive a briefing on effective antimosquito measures, are issued with nets and repellant, and are supervised in taking chemoprophylactic tablets. Unfortunately, even these measures were not adequately followed in our disciplined group. Seven of 150 British soldiers on a five week exercise in central Kenya developed symptomatic falciparum malaria while taking proguanil-chloroquine chemoprophylaxis. Symptoms started between two and 10 days before the soldiers' return to Britain, and the diagnosis was made between five and 13 days after the first symptoms developed. The index patient was severely ill with $50 \%$ parasitaemia: he required intensive care, exchange blood transfusion, and haemofiltration for acute renal failure.

We did not measure compliance with chemoprophylaxis biochemically. The army's policy with regard to chemoprophylaxis, however, was amended in June last year so that mefloquine will be used in future rather than proguanilchloroquine. This should improve compliance and thus effectiveness.

The index patient made us aware that others in his group were at risk owing to common exposure in an area with a high rate of transmission. Subsequently 21 men were traced and screened. This detected two further cases and enabled earlier and definitive treatment of this potentially fatal condition. 
We concluded that despite education and high motivation in an organised group of travellers simple preventive measures were not observed. Guidelines, however, are regularly updated, ${ }^{2}$ and doctors advising travellers should be aware of current advice.

J H MILLER

Military Wing,

Musgrave Park Hospital,
Belfast BFPO 801 Registrar

Nuffield Department of Clinical Medicine,

John Radcliffe Hospital,

Oxford OX3 9DU

1 Miller $\mathrm{JH}$, Byers $M$, Whiteoak $\mathrm{R}$, Warrell DA. Imported falciparum malaria in British troops returning from Kenya. $f$ $R$ Army Med Corps (in press).

2 Bradley D. Prophylaxis against malaria for travellers from the Uradley D. Prophylaxis against malaria for
United Kingdom. BMF 1993;306:1247-52.

\section{No documentary evidence of bribery by German hospital directors}

EdITOR,-On behalf of the German Chamber of Physicians, I wish to comment on Helmut L Karcher's report on accusations of bribery against German hospital directors. ${ }^{1}$ At the end of May the association of all German public health insurance companies said in a statement that directors of 50 out of 51 heart centres in western Germany were to blame for having accepted bribes from producers of artificial heart valves. The news magazine $D e r$ Spiegel published these accusations. ${ }^{2}$

In fact, no such nationwide scandal exists. When the public health insurance companies had to prove their accusations at a special meeting of the health committee of the German Bundestag on 1 June they claimed only 12 cases of bribery without naming the heart centres of hospital directors. Even three months later they were not able to support their accusations with documentary evidence.

There are no indications that bribery is common in German heart centres. According to the news magazine Focus, however, there are indications that the public health insurance companies themselves spent more than DM1m $(£ 421000)$ in an attempt to gain information about the alleged scandal from insiders. ${ }^{3}$ Karcher's article was written as though the story was true, but the story was a hoax.

ALEXANDER DÜCKERS

Pressestelle der deutschen Ärzteschaft,

D-50931 Cologne,

Germany

1 Karcher HL. German hospital directors accused of bribery. $B M \Im$ 1994;309:1588-9. (18 June.)

2 Bares oder einen BMW. Der Spiegel 1994;22:92-8.

3 Kowalski M. Herzklappenaffăre: Flop für Krankenkassen.

Focus 1994;31:18-21.

\section{New treatments for benign prostatic hypertrophy}

EDrToR,-Roger S Kirby and M C Bishop's examination of treatment of benign prostatic hypertrophy is timely, ${ }^{1}$ given the growing number of methods of treatment that are being advocated and the emerging evidence that the volume of unmet need for treatment in the population is large. ${ }^{2}$ We believe, however, that the arguments advanced by Kirby are not supported by the evidence. In the absence of data from randomised controlled trials his conclusions concerning alternative treatments can be only speculative. Unfortunately, depite continued uncertainty about this issue, urologists in Britain have been reluctant to participate in a randomised controlled trial comparing transurethral resection of the prostate with open surgery.

Bishop argues that patients with mild lower urinary tract symptoms are best left alone, a view with which we concur. ${ }^{3}$ Apart from consideration of the balance of benefits and risks, the cost implications of advocating any of these innovative treatments for such men is enormous and the treatments should be undertaken only for good reason. There is therefore an urgent need to evaluate them properly. Before this is done, however, several issues that are insufficiently emphasised by Kirby and Bishop need to be resolved. Are the treatments seen as a substitute for transurethral resection of the prostate among patients currently offered treatment? Is it envisaged that they will be offered to patients with less severe disease than those currently being treated? What measure of outcome will be used, given the lack of concordance between symptoms and urinary flow? And as drug treatment may need to be continued for many years, what is the most appropriate time at which to measure outcome?

Kirby may be correct in saying that urologists unprepared to grasp the future will be left behind. The history of medicine is, however, littered with those who rushed to embrace new technologies only to abandon them when the initial enthusiasm proved unfounded.' The question of who should pay also arises. At present health authorities and general practice fundholders should purchase these new treatments only if they are part of a randomised controlled trial.

\section{MARTIN MCKEE} Senior lecture NICK BLACK Reader

DUNCAN HUNTER Research fellow COLIN SANDERSON Senior lecturer

Department of Public Health and Policy,

Health Services Research Unit,

London School of Hygiene and Tropical Medicine, London WC1E 7HT

1 Kirby RS, Bishop MC. Are the days of transurethral resection of prostate for benign prostatic hyperplasia numbered? $B M$ 1994;309:716-8. (17 September.)

2 Hunter DJW, McKee CM, Black NA, Sanderson CFB. Urinary symptoms: prevalence and severity in British men aged 55 and over. $₹$ Epidemiol Community Health (in press).

3 Doll HA, Black NA, McPherson K. Transurethral resection of the prostate for benign prostatic hypertrophy: factors assothe prostate for benign prostatic hypertrophy: factors asso-
ciated with a successful outcome at one year. $\mathrm{Br} \&$ Urol ciated with a succe

4 Barry MJ, Cockett ATK, Holtgrewe HL, McConnell JD, Barry MJ, Cockett ATK, Holtgrewe HL, McConnell JD,
Sihelnik SA, Winfield HN. Relationship of symptoms of Sihelnik SA, Winfield HN. Relationship of symptoms of
prostatism to commonly used physiological and anatomic prostatism to commonly used physiological and anatomic
measures of the severity of benign prostatic hyperplasia. $f$ Urol 1993;150:351-8.

5 Beeson P. Changes in medical therapy. Medicine 1980;59:79-84.

\section{Supervised administration of methadone by pharmacists}

EDITOR,-Supervision of the administration of methadone by community pharmacists has benefits beyond the prevention of "street leakage." "The risks of loss or theft of the drug, binging, injecting, and overdose are minimised; trust between doctors and patients is enhanced; and as a reward for progress in treatment patients may be given more than one day's supply to take home. A scheme similar to that in Glasgow ${ }^{1}$ has run in West Glamorgan since 1991, with 25 pharmacists each supervising up to 15 patients. The anxieties expressed by pharmacists to Robert T A Scott and colleagues ${ }^{1}$ have not been justified in practice.

A new scheme in Mid Glamorgan has been straightforward to implement. The local pharmaceutical committee agreed the protocol and circulated it to all pharmacists. In both schemes scripts to be supervised are stamped to be easily identifiable. All patients newly prescribed methadone have their consumption supervised daily, Monday to Saturday. Pharmacists do not enforce the scheme but telephone the prescriber regarding non-compliance so that appropriate action can be taken.

P D Thomas's criticisms seem misplaced. ${ }^{2}$ Both sets of guidelines referred to by Scott and colleagues emphasise the need for treatment and contact with a doctor over and above the prescription of methadone. ${ }^{34}$ It is perhaps surprising that neither refers to supervised consumption. The suggestion that prescribers should be responsible for supervision ignores both the unwillingness of many general practitioners even to prescribe and the number of patients per doctor seen by specialist services. Similar concerns over confidentiality and privacy were expressed when pharmacists first provided needle exchange, but pharmacists are now generally seen by drug misusers as "drug user friendly." The reasons for a prescription of methadone are understood by the pharmacist irrespective of where the drug is consumed. Three pharmacists in our schemes have rearranged their premises with privacy in mind, and others may follow. We would emphasise that pharmacists undertake supervision because they recognise the benefits for patients and the public; they receive only the dispensing fee.

Community pharmacists' supervision of consumption of methadone has many advantages. With collaboration between professional groups it can be straightforward to implement. It should be considered wherever centralised methadone maintenance clinics with supervised dispensing on site are impractical.

ANDREW J MCBRIDE
Consultant psychiatrist
IMAD M ALI
Senior registrar

Mid Glamorgan CF38 1RN

ROSEMARY ATKINSON Consultant psychiatrist

Central Clinic

Swansea,

West Glamorgan

1 Scott RTA, Burnett SC, McNulty H. Supervised administration of methadone by pharmacists. $B M \mathcal{F} 1994 ; 308: 1438$. (28 May.)
Thomas PD. Doctors should supervise administration of methadone. BMF 1994;309:53-4. (2 July.)

3 Advisory Council on the Misuse Of Drugs. AIDS and drug misuse update. London: HMSO, 1993:42-9.

4 Department Of Health, Scottish Home and Health Department, Welsh Office. Drug misuse and dependence: guidelines on clinical management. London: HMSO, 1991.

\section{Computer training for doctors and students}

EDITOR,-We agree with the comments by Ronald LaPorte and colleagues ${ }^{1}$ and Ray Jones and Sue Kinn. ${ }^{2}$ The information superhighway, an important technical development of immense potential impact in clinical medicine, will not fulfil its potential if doctors do not, will not, or cannot use it because they do not know how. Education is clearly the key-a fact recognised by the General Medical Council, which has stated that "a working knowledge of modern medical information technology will be essential to the doctor of the future." 3

For some years our unit has run a course in information technology as part of the first year curriculum at Leeds University Medical School, teaching skills necessary to use computers and networks (accessing network information, word processing, use of spreadsheets and databases) and emphasising the use of computers as a source of information for help with practical problems. 